\title{
Global meteorological drought - Part 1: Probabilistic monitoring
}

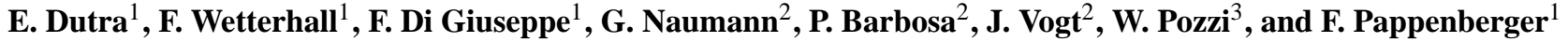 \\ ${ }^{1}$ European Centre for Medium-Range Weather Forecasts, Reading, UK \\ ${ }^{2}$ European Commission, Joint Research Centre, Institute for Environment and Sustainability, Ispra, Italy \\ ${ }^{3}$ Group on Earth Observations, Geneva, Switzerland
}

Correspondence to: E. Dutra (emanuel.dutra@ecmwf.int)

Received: 11 December 2013 - Published in Hydrol. Earth Syst. Sci. Discuss.: 17 January 2014

Revised: - Accepted: 15 June 2014 - Published: 24 July 2014

\begin{abstract}
Near-real-time drought monitoring can provide decision-makers with valuable information for use in several areas, such as water resources management, or international aid. One of the main constrains of assessing the current drought situation is associated with the lack of reliable sources of observed precipitation on a global scale available in near-real time. Furthermore, monitoring systems also need a long record of past observations to provide mean climatological conditions. To address these problems, a novel probabilistic drought monitoring methodology based on ECMWF probabilistic forecasts is presented, where probabilistic monthly means of precipitation were derived from short-range forecasts and merged with the long-term climatology of the Global Precipitation Climatology Centre (GPCC) data set. From the merged data set, the standardised precipitation index (SPI) was estimated. This methodology was compared with the GPCC first guess precipitation product as well as SPI calculations using the ECMWF ERAInterim reanalysis and Tropical Rainfall Measuring Mission (TRMM) precipitation data sets. ECMWF probabilistic forecasts for near-real-time monitoring are similar to GPCC and TRMM in terms of correlation and root mean square errors, with the added value of including an estimate of the uncertainty given by the ensemble spread. The real-time availability of this product and its stability (i.e. that it does not directly depend on local rain gauges or single satellite products) are also beneficial in the light of an operational implementation.
\end{abstract}

\section{Introduction}

Droughts constitute a costly natural hazard that impacts different sectors of society and different countries according to their vulnerability (EM-DAT, 2013). Regional- to largescale droughts are driven by a prolonged precipitation deficit which mainly impact agriculture and hydrology. Depending on the demand on water resources, this can then lead to water scarcity (Van Loon and Van Lanen, 2013). Near-realtime drought monitoring can be used as an important tool to water resources management, and could be further complemented by drought forecasting (Pozzi et al., 2013). Integrating already-existing drought monitoring and forecasting systems could be possible by a synergic effort among weather forecast centres through international partnerships. This would certainly benefit developing countries which, while more vulnerable to rain deficits, often do not have the needed infrastructures to set up environmental monitoring on an operational basis (Webster, 2013).

The accuracy of operational drought monitoring on a global scale crucially depends on the availability of rainfall estimation, and therefore on the spatial coverage and temporal frequency of in situ observations. The number of quality-controlled observations is not constant over time and is not globally homogeneous. For example, the Global Precipitation Climatology Centre (GPCC, http://gpcc.dwd.de), one of the most used global precipitation data sets, shows that Europe, North America and Australia have dense networks, while regions like North Asia, Tibet, and West and East Africa have significantly fewer stations (Fig. 1). In some cases the differences in the network density can be as big as a factor of 10. There is a general decrease in the number of available stations throughout the globe, in particular in the last decade. A quantitative assessment of the impact of this reduction in in situ observations on the quality of the drought monitoring is not straightforward. For example, Gebremichael et al. (2003) proposed an error uncertainty 

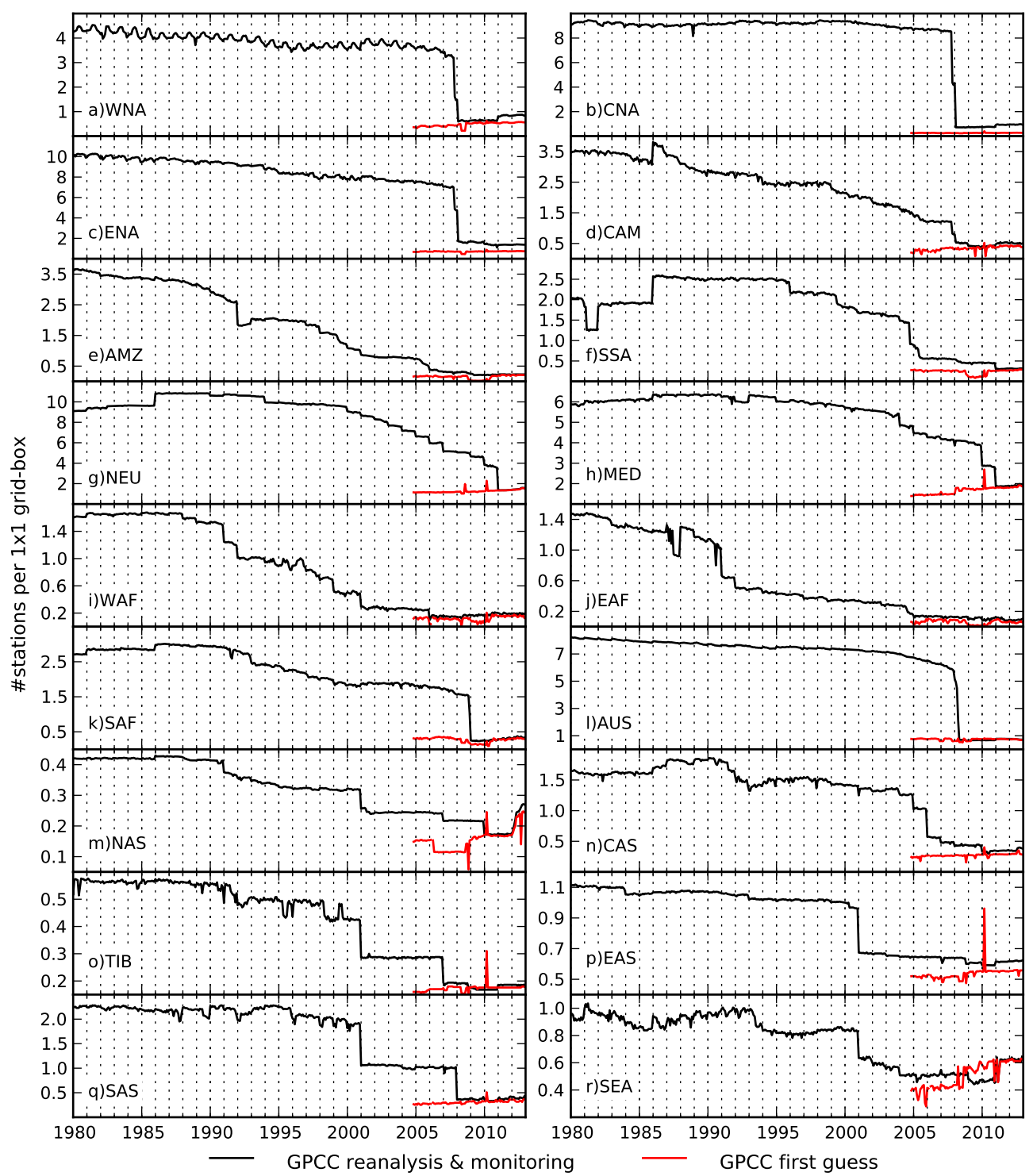

Figure 1. Monthly temporal evolution of the mean number of stations per $1^{\circ} \times 1^{\circ}$ grid box in the different regions (see Table 2 ) present in the GPCC reanalysis (until 2010) and monitoring product (2010 onwards) (black line) and GPCC first guess product (red line).

analysis applied to a global data set of precipitation, and found that at a $2.5^{\circ}$ scale, $8-10$ gauges are required to allow a good error uncertainty estimate.

Indeed several studies (e.g. Belo-Pereira et al., 2011; Dinku et al., 2007; Dutra et al., 2013b; Liebmann et al., 2012) have already documented the large observation error affecting regions with low station coverage, even after offline post-processing and quality control has taken place. Especially in Africa, a continent with notoriously low observational coverage, Naumann et al. (2014) confirms that the main source of error in drought monitoring arises from inaccuracies in the observed precipitation rather than from the estimation of the distribution parameters used to define the drought indicator.
The decreasing availability of local measurements is also likely to affect model products such as re-analysis whose accuracy is still constrained by the observation network quality. Both for observation and re-analysis products it is not straightforward to define a methodology for uncertainty estimation. This is the main motivation for proposing a new approach for drought monitoring which, by making use of probabilistic forecast systems, has the built-in advantage of providing a range of possible values. The new product is tested using the ECMWF ensemble forecasting system and makes use of precipitation fields generated during the first $0-48 \mathrm{~h}$ of model integration of all the 51 ensemble members (Buizza et al., 2007). The system is used to produce a distribution of rainfall monthly means from which drought indices are 
derived. The idea behind it is that model outputs at very short lead times are likely not to be strongly affected by model errors and therefore could provide comparable quality of reanalysis outputs. On the other hand, short-range forecast is less sensitive to changes in observations and, when compared to re-analysis outputs or observational data sets, has the additional benefit of providing an estimate of uncertainty given by their ensemble systems.

The possibility of using short-range forecast for global drought monitoring is investigated by comparing its performance with more established approaches based on observations (Sects. 2 and 3 ) and reanalysis products. The added benefits of generating drought indices in a probabilistic framework are discussed in the last section.

\section{Data and methods}

\subsection{Precipitation data sets}

To show how different precipitation sources can lead to different drought estimations, in this study we have selected a mixture of observation and modelling data sets as input to the drought monitoring system (Table 1).

The first is an observational data set that includes three products from the Global Precipitation Climatology Centre (GPCC, http://gpcc.dwd.de): the full reanalysis version 6 (GPCC_FD; Schneider et al., 2011b) available from 1901 to 2010; the monitoring product version 4 (GPCC_MP; Schneider et al., 2011a) available from 2007 to 2 months prior to present $^{1}$; and the first guess product (GPCC_FG; Ziese et al., 2011b) available from August 2004 to present expired month ${ }^{1}$. The GPCC monthly precipitation data sets are available globally on a $1^{\circ} \times 1^{\circ}$ regular grid.

The second data set is a satellite-based one, the Tropical Rainfall Measuring Mission (TRMM, Huffman et al., 2007), and is available between $50^{\circ} \mathrm{N}$ and $50^{\circ} \mathrm{S}$, with a regular $0.25^{\circ}$ resolution from 1998 to two months prior to present. Finally, the third data set is a model-based one. The ECMWF ERA-Interim reanalysis (ERAI; Dee et al., 2011) is available from 1979 to present expired month with an approximate resolution of $0.7^{\circ}$. Even if these three precipitation data sets are generated from different sources - rain gauges only in the case of GPCC, satellite and rain gauges for TRMM and numerical weather forecasts in the case of ERAI - they are provided as a "proxy" for the real-state and are in this sense a deterministic estimate which does not account for uncertainties.

Following the new idea that this paper tries to explore, a new data set based on the ECMWF short-range ensemble forecast system (known as ENS; Buizza et al., 2007) is created. From March 2008 until January 2010 forecasts are gen-

\footnotetext{
${ }^{1}$ The precipitation data sets have been continuously updated every month, last checked in July 2014, and that is expected to continue in the future.
}

erated with a resolution of about $0.45^{\circ}$ and after that with a resolution of $0.28^{\circ}$. An amalgamation of forecasts with lead times of $0-48 \mathrm{~h}$ is used to generate monthly means. Since ENS consists of 51 members, this results in an ensemble of 51 monthly means. ECMWF has been producing ensemble forecasts prior to 2008, but only recent forecasts were used, since they have a set of associated re-forecasts (or hindcasts) which are needed to compute forecasts anomalies. The availability of a historical forecast is of primary importance for the scope of bias correction (Di Giuseppe et al., 2013a). The ENS data set is composed therefore of very short-range forecasts and they provide a probabilistic estimate of rainfall amount.

\subsection{Drought indices}

There are several examples of operational drought monitoring systems on the global (e.g. Ziese et al., 2011a) and continental scale (e.g. Svoboda et al., 2002; Ziese et al., 2011a). On regional to local scales, there are also several examples of studies evaluating different drought indices and/or multivariate indexes (Hao and AghaKouchak, 2013; Sepulcre-Canto et al., 2012; Shukla et al., 2011; Tadesse et al., 2004). The standardised precipitation index from Mckee et al. (1993) is selected in this study as a generic drought index, since it is widely used and recommended by the World Meteorological Organization (WMO). As an independent drought indicator we also consider the fraction of absorbed photosynthetically active radiation (fAPAR) anomalies which are a measure of the fraction of the solar energy absorbed by the vegetation. fAPAR anomalies are known to be strongly related to water stress and are considered a good indicator to detect and assess drought impacts on vegetation canopies (Sepulcre-Canto et al., 2012).

All products are interpolated to a common grid of $1^{\circ} \times 1^{\circ}$, the same grid as the GPCC products, with global coverage. The comparison of the drought conditions focuses on large regions adapted from Giorgi and Francisco (2000) (Table 2, Fig. 2). These regions were identified in terms of homogeneous climatic regions and are wide enough to contain enough grid points for robust statistics calculated in the next sections.

\subsubsection{The standardised precipitation index (SPI)}

The SPI is a transformation of the accumulated precipitation in a specific time period (typically the previous 3,6 , and 12 months, denoted as SPI-3, SPI-6, and SPI-12, respectively) into a normal distribution of mean zero and standard deviation 1.

The precipitation normalisation for the SPI calculations at different timescales was based on the 30-year period 19812010 for the GPCC reanalysis and ERAI data sets by fitting a gamma distribution (following the method described by Dutra et al., 2013a) and for the period 1998-2012 for TRMM 
Table 1. Precipitation products description.

\begin{tabular}{|c|c|c|c|c|c|}
\hline & Product & Type & Acronym & Details & References \\
\hline \multirow{5}{*}{ 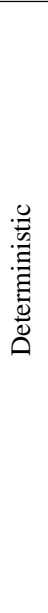 } & $\begin{array}{l}\text { GPCC full } \\
\text { reanalysis } \\
\text { version } 6\end{array}$ & Rain gauges & GPCC_FD & $\begin{array}{l}\text { 1901-2010, } \\
\text { Monthly Global, } \\
1^{\circ} \times 1^{\circ} \text { lat/lon }\end{array}$ & Schneider et al. (2011b) \\
\hline & $\begin{array}{l}\text { GPCC monitoring } \\
\text { product version } 4\end{array}$ & & GPCC_MP & $\begin{array}{l}\text { Jan } 2007-\text { two months prior to present } \\
\text { Monthly Global, } 1^{\circ} \times 1^{\circ} \text { lat/lon } \\
1^{\circ} \times 1^{\circ} \text { lat/lon }\end{array}$ & Schneider et al. (2011a) \\
\hline & $\begin{array}{l}\text { GPCC first } \\
\text { guess product }\end{array}$ & & GPCC_FG & $\begin{array}{l}\text { Aug } 2004 \text {-present expired month }{ }^{1}, \mathrm{M} \\
\text { Monthly Global, } \\
1^{\circ} \times 1^{\circ} \text { lat/lon }\end{array}$ & Ziese et al. (2011b) \\
\hline & $\begin{array}{l}\text { Tropical Rainfall } \\
\text { Measuring Mission } \\
\text { 3B43 V7 }\end{array}$ & Satellite & TRMM & $\begin{array}{l}\text { Jan } 1998 \text {-two months prior to present } \\
\text { Monthly } 50^{\circ} \mathrm{S}-50^{\circ} \mathrm{N} \\
0.25^{\circ} \times 0.25^{\circ} \text { lat/lon }\end{array}$ & Huffman et al. $(2010,2007)$ \\
\hline & $\begin{array}{l}\text { ECMWF ERA-Interim } \\
\text { reanalysis }\end{array}$ & Re-analysis & ERAI & $\begin{array}{l}\text { 1979-present expired month }{ }^{1} \text {, } \\
\text { Daily, } \\
\approx 0.7^{\circ} \times 0.7^{\circ} \text { lat } / \text { lon }\end{array}$ & Dee et al. (2011) \\
\hline 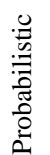 & $\begin{array}{l}\text { ECMWF short-range } \\
\text { ensemble forecasts }\end{array}$ & Short-range forecast & ENS & $\begin{array}{l}\text { Mar 2008-present }{ }^{1} \\
\text { Daily Global } \approx 0.45^{\circ} \times 0.45^{\circ}\left(\text { until Jan }^{1} 2010\right) \\
\text { Global } \approx 0.28^{\circ} \times 0.28^{\circ}\left(\text { to present }^{~}\right)\end{array}$ & Buizza et al. (2007) \\
\hline
\end{tabular}

Table 2. List of regions used in this study. Adapted from Giorgi and Francisco (2000) using only land points (see also Fig. 2).

\begin{tabular}{llll}
\hline Name & Acronym & Latitude & Longitude \\
\hline Australia & AUS & $45-11^{\circ} \mathrm{S}$ & $110-155^{\circ} \mathrm{E}$ \\
Amazon Basin & AMZ & $20^{\circ} \mathrm{S}-12^{\circ} \mathrm{N}$ & $82-34^{\circ} \mathrm{W}$ \\
Southern South America & SSA & $56-20^{\circ} \mathrm{S}$ & $76-40^{\circ} \mathrm{W}$ \\
Central America & CAM & $10-30^{\circ} \mathrm{N}$ & $116-83^{\circ} \mathrm{W}$ \\
Western North America & WNA & $30-60^{\circ} \mathrm{N}$ & $130-103^{\circ} \mathrm{W}$ \\
Central North America & CAN & $30-50^{\circ} \mathrm{N}$ & $103-85^{\circ} \mathrm{W}$ \\
Eastern North America & ENA & $25-50^{\circ} \mathrm{N}$ & $85-60^{\circ} \mathrm{W}$ \\
Mediterranean Basin & MED & $30-48^{\circ} \mathrm{N}$ & $10^{\circ} \mathrm{W}-40^{\circ} \mathrm{E}$ \\
Northern Europe & NEU & $48-75^{\circ} \mathrm{N}$ & $10^{\circ} \mathrm{W}-40^{\circ} \mathrm{E}$ \\
Western Africa & WAF & $12^{\circ} \mathrm{S}-18^{\circ} \mathrm{N}$ & $20^{\circ} \mathrm{W}-22^{\circ} \mathrm{E}$ \\
East Africa & EAF & $12^{\circ} \mathrm{S}-18^{\circ} \mathrm{N}$ & $22-52^{\circ} \mathrm{E}$ \\
Southern Africa & SAF & $35-12^{\circ} \mathrm{S}$ & $10^{\circ} \mathrm{W}-52^{\circ} \mathrm{E}$ \\
Southeast Asia & SEA & $11^{\circ} \mathrm{S}-20^{\circ} \mathrm{N}$ & $95-155^{\circ} \mathrm{E}$ \\
East Asia & EAS & $20-50^{\circ} \mathrm{N}$ & $100-145^{\circ} \mathrm{E}$ \\
South Asia & SAS & $5-30^{\circ} \mathrm{N}$ & $65-100^{\circ} \mathrm{E}$ \\
Central Asia & CAS & $30-50^{\circ} \mathrm{N}$ & $40-75^{\circ} \mathrm{E}$ \\
Tibet & TIB & $30-50^{\circ} \mathrm{N}$ & $75-100^{\circ} \mathrm{E}$ \\
North Asia & NAS & $50-70^{\circ} \mathrm{N}$ & $40-180^{\circ} \mathrm{E}$ \\
\hline
\end{tabular}

using the methodology described by Naumann et al. (2012). The SPI calculations for ERAI after 2010 use the gamma parameters fitted for the period 1981-2010 using ERAI.

For ENS, a slightly different approach is used. The ENS forecast anomalies $\left(F^{\prime}\right)$ for each month are derived by $F^{\prime}=$ $F / \mathrm{FC}$, where $F$ is the original ensemble with 51 monthly means and FC is the model climate. The model climate (FC) is derived by binning all the hindcasts over the past 18years (20 since July 2012), each with 5 ensemble members

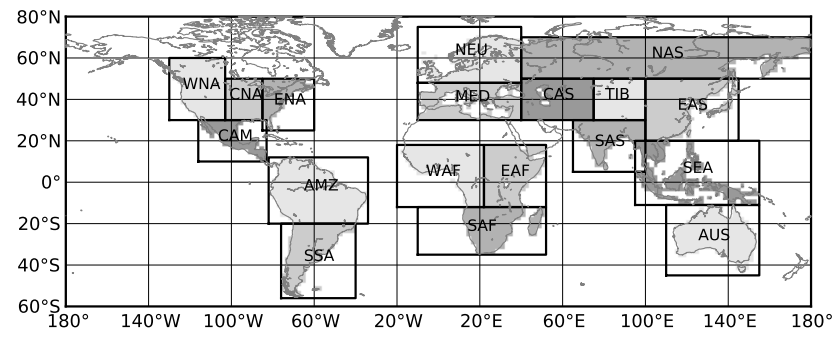

Figure 2. Regions used in the analysis adapted from Giorgi and Francisco (2000). See also Table 2.

for all calendar months, resulting in 5 (weeks) $\times 18$ (years $) \times$ 5 (ensemble members) $=450$ samples. The ENS probabilistic monthly forecast anomalies were then multiplied by the long-term climatology of the GPCC reanalysis.

Since SPI is calculated using precipitation accumulated over a period of time, the main issue in an operational system is the delay compared to the real-time which affects all data sets, especially if based on observation or reanalysis products. Depending on the providers these delays can be as long as few months. As an example Fig. 3 exemplifies the calculation of SPI-6 under the hypothesis that there is a 2-month delay in the release of the official GPCC monitoring product. In this case the previous 2 months can be taken from the GPCC first guess or ENS and the initial 4 months are taken from the GPCC monitoring product. The SPI using the GPCC first guess or ENS only differs from the calculation regarding the the precipitation data in the previous 2 months. The added 


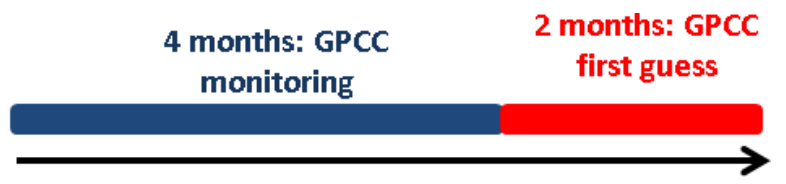

Using GPCC products: SPI 6 months

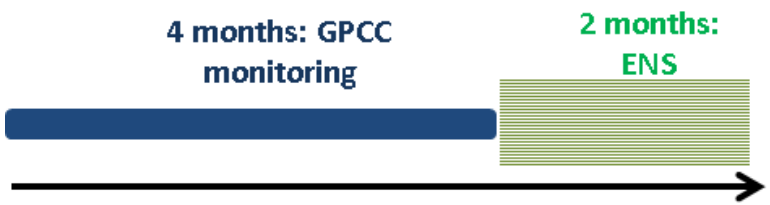

Using GPCC+ENS: SPI 6 months

Figure 3. Schematic of the SPI 6 calculation in near-real time using GPCC monitoring and first guess products (top) and GPCC monitoring and ENS (bottom).

benefit of ENS is that it also provides an ensemble of possible forecasts. Both SPI data sets share the same 1, 4, and 10 months of GPCC monitoring for the SPI 3, 6, and 12, respectively. The transformation to SPI is then done by fitting parameters of the Gamma distribution for the period 19812010 using the GPCC reanalysis. The decision to calculate the SPI from the different data sets using the base period 1981-2010 (except TRMM) was motivated by the opportunity to mimic an operational system that would use a fixed base period for the SPI calculations. If the base period was updated every month, the past SPI evolution would change. A detailed evaluation of the impact of the base period frequency update in an operational system is out of the scope of the current manuscript, but it is expected to mainly affect extreme SPI values following extremely wet or dry seasons.

\subsubsection{The photosynthetically active radiation (fAPAR)}

The fraction of absorbed photosynthetically active radiation (fAPAR) represents the fraction of the solar energy which is absorbed by vegetation. fAPAR is a biophysical variable directly correlated with the primary productivity of the vegetation, since the intercepted PAR is the energy (carried by photons) underlying the biochemical productivity processes of plants. Due to its sensitivity to vegetation stress, fAPAR has been proposed as a drought indicator (e.g. Gobron et al., 2007). Indeed droughts can cause a reduction in the vegetation growth rate, which is affected by changes either in the solar interception of the plant or in the light use efficiency.

Similarly to what was done for precipitation, fAPAR is derived from the multispectral images acquired by the VEGETATION sensor onboard the SPOT satellite, and the values are estimated using the algorithm developed by Gobron et al. (2004). These images are produced by the Flemish institute for technological research (VITO). fAPAR anomalies are produced for every 10-day period and the aggregated to
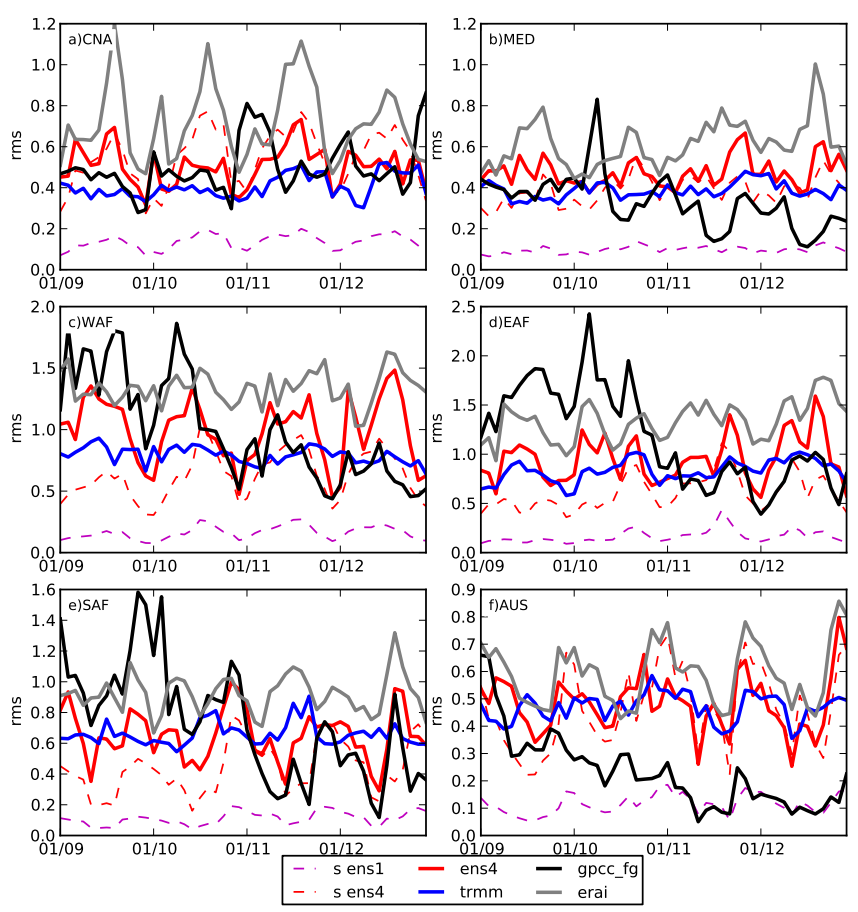

Figure 4. SPI-3 time series of the spread around the ensemble mean in ENS1 (dashed magenta) and ENS4 (dashed red), and root mean square (RMS) error of ENS4 ensemble mean (red); TRMM (blue), GPCC_FG (black) and ERAI (grey) for six different regions. The RMS errors are calculated in respect to GPCC.

monthly values as follows:

fAPAR $_{\text {anomaly }}=\frac{x_{t}-\bar{x}}{\sigma}$,

where $x_{t}$ is the fAPAR of the 10-day period $t$ of the current year and, $\bar{x}$ is the long-term average fAPAR and $\sigma$ is the standard deviation, both calculated for the same 10-day period $t$ using the available time series from 1989 to present. fAPAR anomalies are produced only for pixels that have at least 5 years of data for the given 10-day period.

\section{Results}

\subsection{Ensemble inflation}

One of the advantages of using ENS for precipitation monitoring is the probabilistic nature of the product that allows, to some extent, an estimation of the uncertainty, and could be potentially useful in a decision-making environment. Furthermore, ENS enables a comparison of the ensemble spread (defined as the root mean square, RMS, of the individual ensemble members in relation to the ensemble mean) with the RMSE of the ensemble mean which in a perfect ensemble should be equal (Palmer et al., 2006). Our initial results indicate that the monthly means of ENS had a reduced spread in comparison with the RMSE of the ensemble mean. As a 


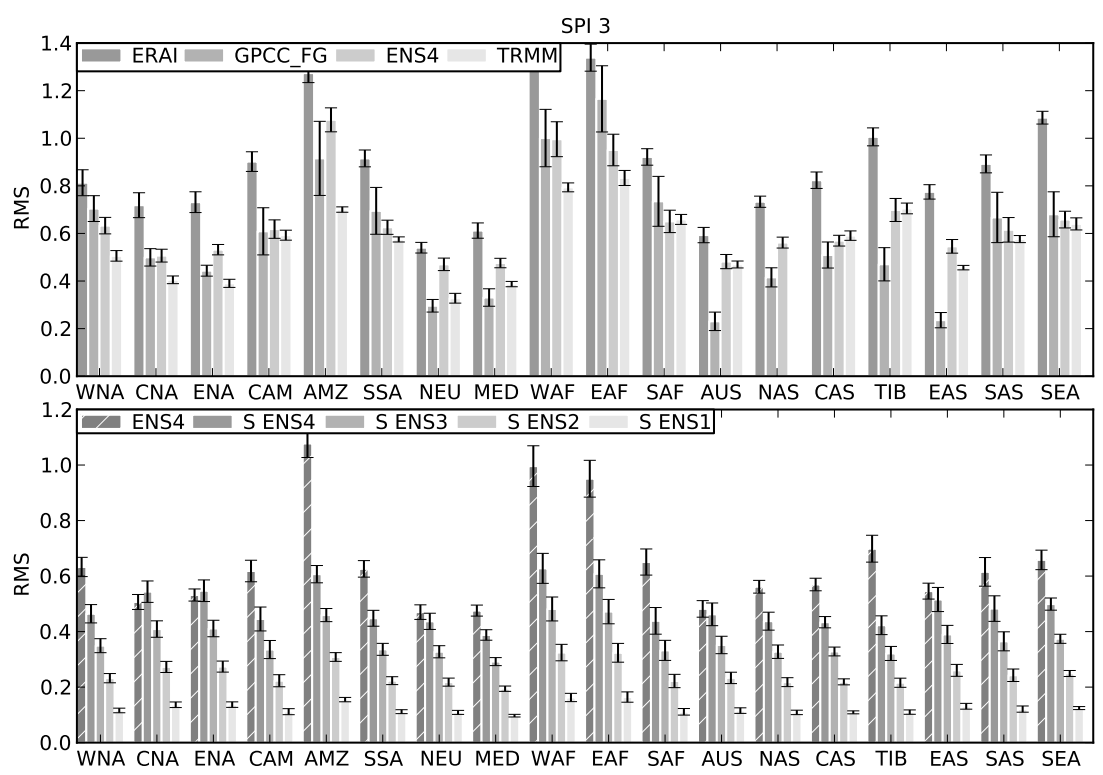

Figure 5. Top: time mean root mean square (RMS) error of the SPI-3 derived from ERAI, GPCC_FG, ensemble mean of ENS4 and TRMM. Bottom: time mean RMS error of the SPI-3 in ENS4 (dashed bars) and the time mean spread about the ensemble mean of ENS4, ENS3, ENS2 and ENS1. The error bars in both panels represent 95\% confidence intervals of the temporal mean (monthly values 2009-2012) assuming a normal distribution.

first approach, a simple inflation was applied to increase the ensemble spread by a factor $a$ :

$\hat{F}=a F+\bar{F}(1-a)$,

where $F$ is the original ensemble and $\bar{F}$ is the ensemble mean. Note that the factor $a$ does not affect the ensemble mean, it merely enhances the spread. Factors ranging from 1 to 4 were used, and are henceforth referred to as ENS1ENS4 (solid versus dashed red lines in Fig. 4, and first and last bar for each region in Fig. 5).

An inflation factor of 4 provided a reasonable match between the spread of the ensemble and the RMSE of the ensemble mean in most regions considering the confidence intervals, except the Amazon, and West and East Africa (Fig. 5). The spatial maps of the spread and RMSE of the ensemble mean show that the RMSE of ENS is higher over the tropical regions, while the ensemble spread is smaller (Fig. S4 in the Supplement). In the extra-tropics there is a reasonable agreement between the ensemble spread and the RMSE of the ensemble mean. It would be possible to optimise the inflation factor for each region (or even grid point), but such optimisation is beyond the scope of this work. Such optimisation would also need to consider different forecast windows (e.g. $12-36 \mathrm{~h}$, or $24-48 \mathrm{~h}$, instead of $0-48 \mathrm{~h}$ ) and should include the observations' uncertainty. The high values of the RMSE over tropics are also present in both ERAI and TRMM (Fig. S4 in the Supplement). This suggests that in those areas there is a large uncertainty, which could also be due to observation errors in GPCC. These errors should be taken into account when comparing the spread and the RMSE.

\subsection{Drought monitoring}

To evaluate the performance of the different precipitation in terms of SPI, the root mean square errors (RMSE) were computed for each region. The GPCC full reanalysis data set is taken as a benchmark. ERAI shows the highest RMSE, followed by ENS and TRMM (Fig. 4 for a subset of six regions, and Fig. S1 in the Supplement for the remaining regions). The temporal evolution of GPCC first guess RMSE displays a negative trend in most of the regions. As already discussed, between 2009 and 2010 the GPCC first guess and reanalysis products differ in the number of stations, while from 2010 onwards the monitoring product uses a similar number of stations as the first guess (Fig. 1). The apparent negative trend in the RMSE can be due to the verification data set, which from 2010 onwards is based on the GPCC monitoring product. These results show that the relation between GPCC's first guess and the reanalysis (or monitoring) has changed in the last years mainly due to the decrease in the number of stations used in the production of the data sets. The GPCC final and first release (first guess) products have had a similar number of stations since 2010 onwards. Before 2010 the GPCC final release had more stations then the first guess, showing an effort of GPCC to collect station data that is not easily available in near-real time. Changes in the number of rain gauges included in the GPCC product are likely to impact the temporal homogeneity of the data set regarding 
drought monitoring where past climate is used to estimate anomalies.

The temporal mean of the RMSE of the SPI-3 from the different products also highlights the larger uncertainty of the first guess product that tends to have larger error bars in most regions (Fig. 5). In most regions the RMSE of TRMM and ENS are similar, giving a first indication that ENS can be used with some confidence for drought monitoring. For longer lead times (see Figs. S2 and S3 in the Supplement) the RMSE of ENS and first guess tend to be very similar and lower than ERAI or TRMM. The reason for this is that ENS and first guess share most of the precipitation with GPCC for the longer lead times.

The temporal grid-point correlation of the different SPI products versus GPCC (Fig. 6 for the SPI-3 and Fig. S6 in the Supplement for the SPI-12) shows a good agreement in the extra-tropics and a reduced agreement in the tropical regions. This is further supported by the spatial means and associated confidence intervals in Figs. S7 and S8 in the Supplement. The poor agreement of ERAI with GPCC in West and East Africa had already been identified by Dutra et al. (2013a) and Di Giuseppe et al. (2013b). However, the correlations of GPCC with the other data sets (TRMM, GPCC first guess and ENS) are also lower in the tropics. These results further support our discussion of the RMSE spatial distribution (Figs. S4 and S5 in the Supplement), suggesting that the GPCC errors/uncertainty in these regions is higher. This is likely to be associated with the high spatial variability of rainfall resulting from deep convection and land-atmosphere feedbacks that can only be captured with very dense observing networks. Considering these limitations of the observing system, and the comparison of the different precipitation products, the use of the ENS precipitation for near-real-time monitoring provides results as plausible as those obtained with GPCC and TRMM.

The large uncertainties in the data sets limit the interpretation and attribution of the main differences between SPI estimations, in particular in tropical regions. To further address this point we would require an independent data set that could be considered as "observed droughts". While such data set does not exist on a global scale, the definition of drought conditions will depend on the impact on several hydrological, agricultural and ecological variables (e.g. Vicente-Serrano et al., 2012). In this study the fAPAR was used as a proxy for drought conditions resulting from the vegetation response to anomalies in water supply. The temporal anomaly correlation of SPI and fAPAR for 1999-2012 is shown in Fig. 7 for SPI12 and Fig. S9 in the Supplement for SPI-3 (ENS and GPCC first guess were not included since they are only available since 2009). The correlations are generally higher for SPI12 in comparison with SPI-3, but the main spatial patterns are similar. It is possible to identify several regions where the fAPAR anomalies have a positive and significant correlation with the SPI. The spatial mean of the grid-point correlations (Fig. S10 in the Supplement for SPI-3 and Fig. S11 in the Supplement for SPI-12) shows that the correlation coefficients between the different SPI estimations and fAPAR anomalies tend to be within the same confidence interval for each region. Therefore, this comparison does not provide a conclusive ranking between the GPCC, TRMM and ERAI. These results also highlight the current difficulty of globally validating meteorological drought. Furthermore, the operational methodology developed for the use of GPCC first guess and ENS also restricts the time period available for the verification.

\subsection{Precipitation monitoring}

The previous results compared the different data sets after the SPI transformation, which includes temporal aggregation and normalisation. Therefore, the results are not directly related to the performance of the original precipitation data sets. The monthly grid-point precipitation anomaly correlation between the different data sets and GPCC for the 2009-2012 (Fig. 8 and Fig. S12 in the Supplement) is similar to those of the SPI-3 (Fig. 6) in the case of TRMM, ERAI and GPCC first guess, while ENS4 generally has lower values. While the SPI-3 ENS4 had a better agreement with GPCC than ERAI, when we evaluate the monthly precipitation ENS4, it has a similar performance as ERAI. This is mainly due to the construction of the SPI using ENS4 that only included the forecast anomalies and was merged with GPCC monitoring (see Fig. 3), while ERAI SPI is completely defined from ERAI past climate. These results show the added value of constructing the SPI using only the previous 2 months of ENS and the remaining data from GPCC.

The temporal correlation only reflects the agreement of the data sets in terms of variability, which is the most important factor in the SPI calculation. On the other hand, the spatial maps of the root mean square error of monthly precipitation anomalies for 2009-2012 show the average magnitude of the error between data sets and are displayed in Fig. S13 in the Supplement and the spatial mean in Fig. S14 in the Supplement. GPCC first guess stands out with higher errors in the tropical regions in terms of precipitation values, while that was not evident in the correlations of precipitation or SPI. ENS4 tends to have similar or lower RMSE than ERAI, while TRMM has the lowest RMSE. These results indicate that the interpretation of the SPI relation between two data sets is not directly translated into the original precipitation, or vice-versa.

As an example of the temporal evolution of the different precipitation data sets and the SPI at different timescales, two recent drought events were selected: the 2010-2011 drought in the Horn of Africa (Fig. 9) and the 2012 drought in the US Great Plains (Fig. S14 in the Supplement). These examples exemplify graphically the evolution of the SPI, in particular the ENS product, and are not meant to evaluate the drought events in detail. The 2010-2011 drought in the Horn of Africa was characterised by two consecutive anomalous 


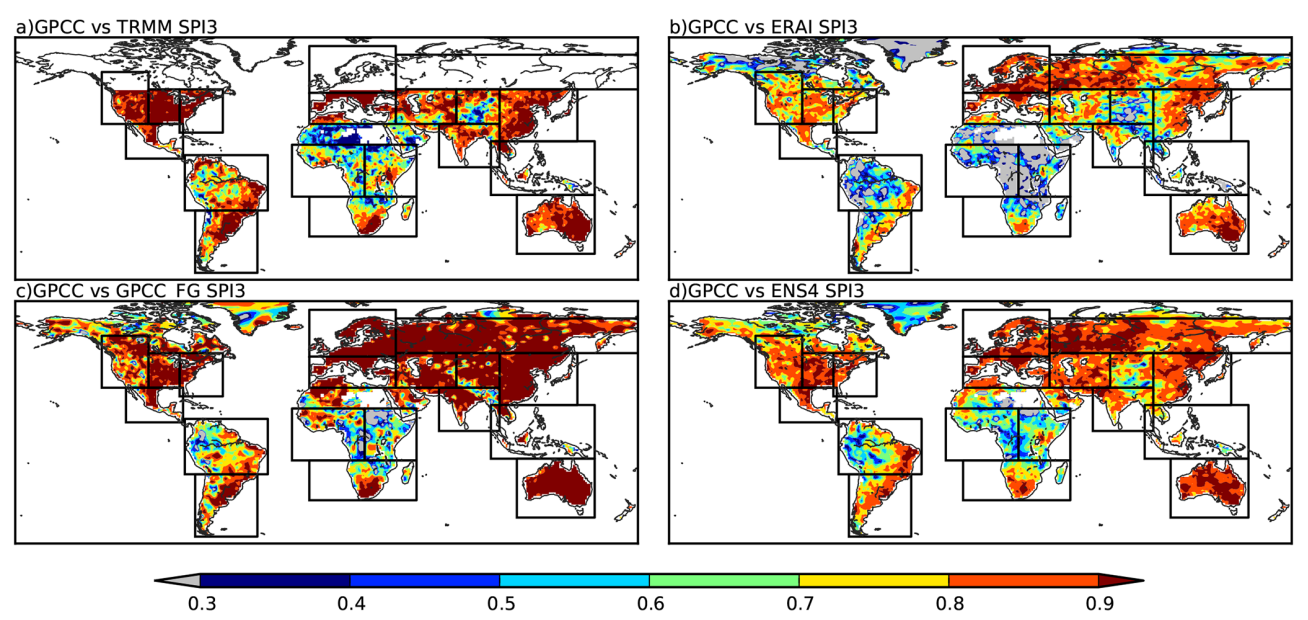

Figure 6. Temporal grid-point correlations of the GPCC SPI-3 (2009-2012) versus (a) TRMM, (b) ERAI, (c) GPCC_FG, and (d) ENS4. Correlations below 0.3 or not statistically significant different from zero are displayed as grey.
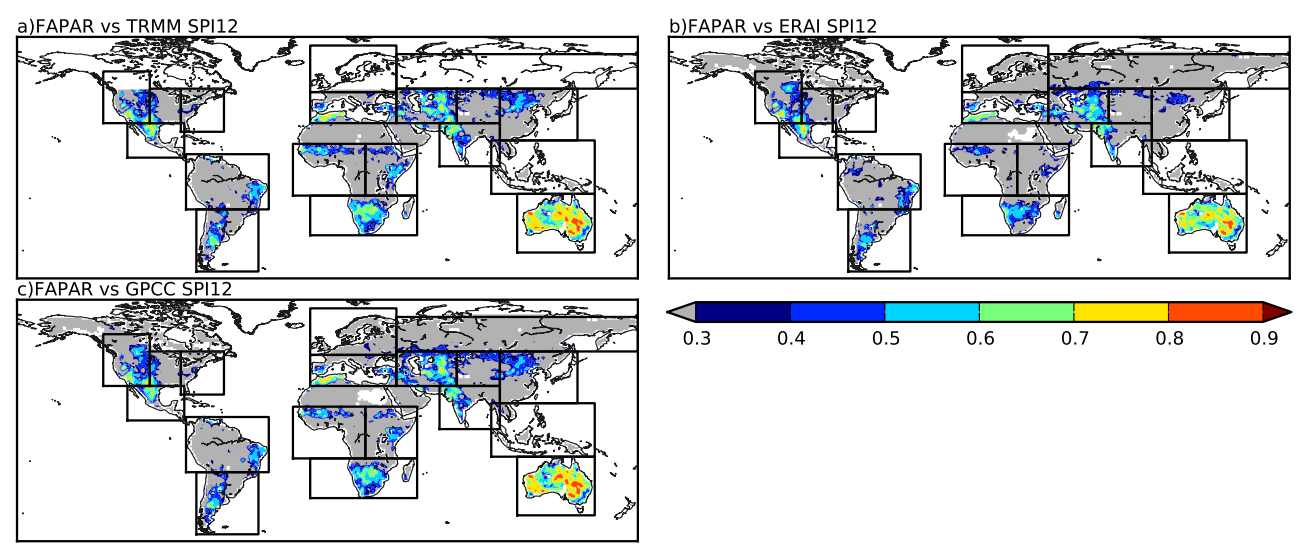

Figure 7. Temporal correlation of fAPAR (1999-2012) versus SPI-12 from (a) TRMM, (b) ERAI, and (c) GPCC. Correlations below 0.3 or not statistically significant different from zero (at $95 \%$ ) are displayed as grey.

dry rainy seasons: October-December 2010 and March-May 2011 (see Dutra et al., 2013b for more details). There is a close agreement between the temporal evolution of GPCC and TRMM and to some extent also ERAI, while the GPCC first guess product presents notable differences (Fig. 9). The time series of ENS precipitation show the impact of the inflation factor from the original spread (ENS1 - dark shading) to the selected four-spread inflation (ENS4 - grey shading). The ensemble spread provided by ENS4 in general covers the range of precipitation estimates from GPCC, TRMM and ERAI. As expected, the ENS4 spread is reduced with increased SPI timescale, as we only use the previous 2 months of precipitation from ENS4 and the remaining from GPCC. The recent 2012 drought in the US Great Plains had a rapid onset during May-July 2012 and Kumar et al. (2013) suggests that the drought could plausibly have arisen from atmospheric noise alone. The precipitation and SPI time series averaged for the Great Plains regions (Fig. S15 in the Supplement) show the dry anomaly from May 2012 onwards that was captured by all products. SPI-3 recovered to normal values in February 2013, SPI-6 in May 2013, while SPI-12 was still below -1 (between -1 and -2 in ENS4) in June 2013.

\section{Discussion and conclusions}

The paper presents a novel probabilistic methodology for near-real-time meteorological drought monitoring. The large reduction of rain gauges employed in global precipitation data sets over the last decade make evident the need for new research on drought monitoring. While the density of rain gauges differs significantly among different regions of the globe, all regions suffer from this desertification of observations. On the other hand, several precipitation products derived from remote sensing post-processing techniques have emerged in recent years. These products can in part mitigate the reduction of in situ observations, but also have limitations associated with short time series, calibration (that also relies on in situ data) and lifetime of the satellites, among others. 


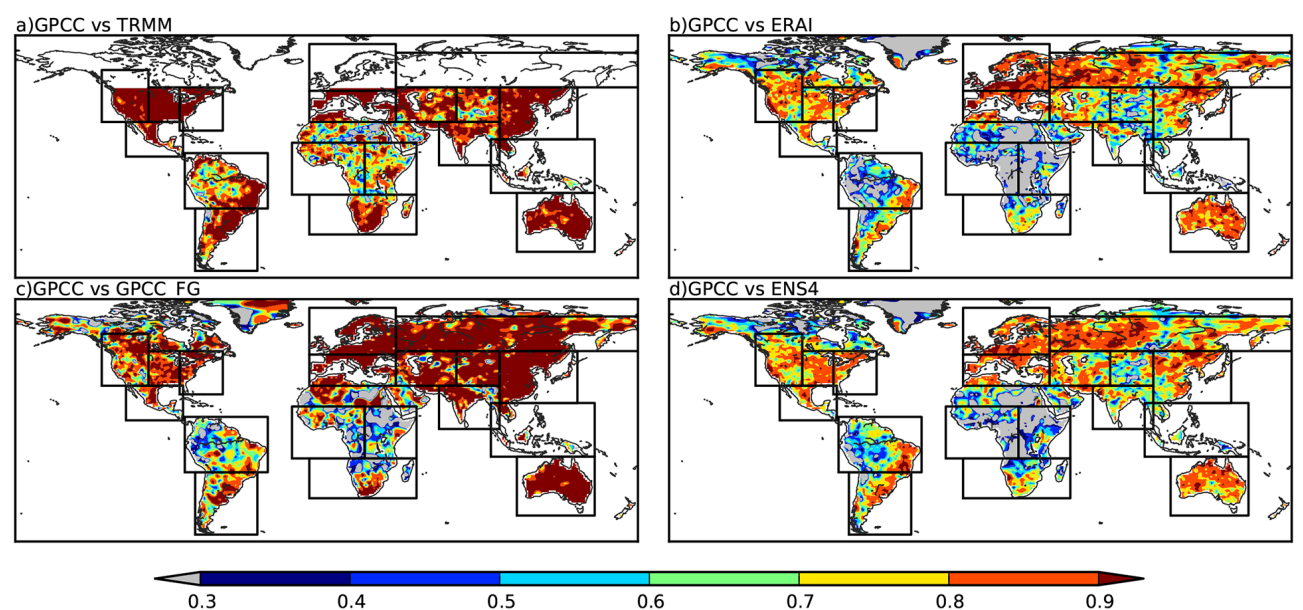

Figure 8. Temporal grid-point correlations of the GPCC monthly precipitation versus (a) TRMM, (b) ERAI, (c) GPCC_FG, and (d) ENS4. The correlations were calculated for the overlap period 2009-2012 and the mean annual cycle of the period was removed from each data set prior to the correlations calculation.

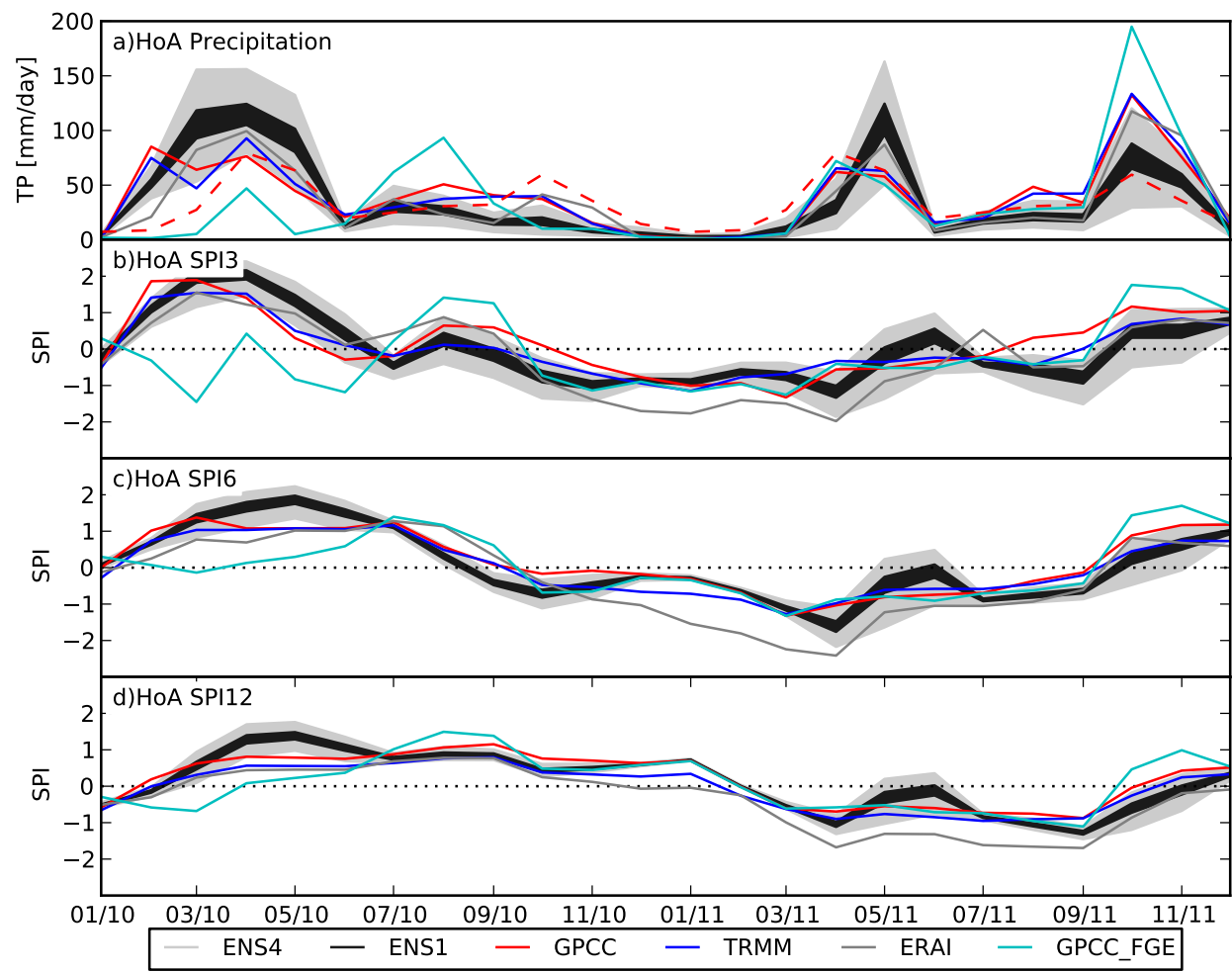

Figure 9. Spatial averages over the Horn of Africa region $\left(3^{\circ} \mathrm{S}-12^{\circ} \mathrm{N}, 40-52^{\circ} \mathrm{E}\right)$ of (a) total precipitation, (b) SPI-3, (c) SPI-6 and (d) SPI12 for the different monitoring products: GPCC_FD (red), TRMM (blue), ERAI (dark grey), GPCC_FGE (cyan). The probabilistic ENS data in shading ranges from the minimum to the maximum (light grey for original ENS and black for the ENS with 4 times spread inflation). In panel (a) the GPCC mean annual cycle is represented by the dashed red curve.

A probabilistic drought monitoring system could be based on different products, and could potentially consider the current uncertainty of near-real-time precipitation observations. In this study the ECMWF ensemble forecasts were used to derive probabilistic estimates of monthly precipitation anomalies. This is possible thanks to the long data set of re-forecasts that are produced operationally (the past 20 years with 5 ensemble members once a week) and which provide the model climate. The probabilistic monthly forecast anomalies were then added to the GPCC reanalysis longterm climatology and a near-real-time SPI is calculated. Our initial results showed that the probabilistic SPI derived with 
this technique is under-dispersive, when compared with the root mean square error of the ensemble mean. By applying an inflation factor of 4 to the ensemble standard deviation, the result is an improved agreement between the ensemble spread around the ensemble mean and the RMSE of the ensemble mean. The selection of the inflation factor can be refined to include the spatial variability of the errors and spread of the ECMWF forecasts.

An independent evaluation of the SPI products was performed by comparing their temporal evolution with the fAPAR anomalies as a proxy to drought conditions associated with soil moisture deficits and its impact on vegetation. Several regions around the globe have a positive correlation between the SPI and the fAPAR. When considering the spatial mean of the grid-point correlations and their associated error bars, it was possible to identify the regions where the vegetation responds directly to meteorological droughts, but it was not possible to identify the best- or worst-performing SPI data set. Therefore, this comparison does not provide a conclusive ranking between GPCC, TRMM and ERAI; instead it highlights the current difficulty of globally validating meteorological drought. A comparison between the original precipitation data sets prior to the SPI transformation show similar results as for SPI-3 for the temporal correlation. On the other hand, when evaluating the RMSE of monthly precipitation the GPCC first guess products have higher errors in some tropical regions, a feature that was not evident in the SPI comparison. The results point to the effect of the SPI procedure in normalising the precipitation time series and suggest that the interpretation of the SPI relation between two data sets is not directly translated into the original precipitation, or vice-versa.

In this study only a single index was considered, and not a multivariate index approach (e.g. Hao and AghaKouchak, 2013; Shukla et al., 2011; Ziese et al., 2011a). The proposed methodology of using the ECMWF probabilistic forecasts to generate monthly (or daily) means of another index is also feasible but would require further evaluation. A potential candidate to include would be the standardised precipitation evapotranspiration index (SPEI, Vicente-Serrano et al., 2010), that in addition to precipitation also considers potential evapotranspiration (that could be simply derived from temperature forecasts). Evapotranspiration can amplify drought events (Teuling et al., 2013), but care should be taken when using simple calculations of potential evapotranspiration (Sheffield et al., 2012). Another option could be soil moisture that is also available in the ECMWF probabilistic forecasts, or a combination of different indices (e.g. Sepulcre-Canto et al., 2012). Future work could include the evaluation of different indexes, and also to increase the update frequency from monthly to weekly.

Considering the limitations of the precipitation near-realtime monitoring and the comparison of the different precipitation products in terms of correlation and RMSE the use of the ENS precipitation for near-real-time monitoring provides products comparably to GPCC and TRMM with the added value of including an estimate of the uncertainty given by the ensemble. The real-time availability of ENS and its stability (i.e. does not directly depend on local rain gauges or single satellite products) are also beneficial for a near-realtime implementation of an operational product.

\section{The Supplement related to this article is available online at doi:10.5194/hess-18-2657-2014-supplement.}

Acknowledgements. This work was funded by the European Commission Seventh Framework Programme (EU FP7) in the framework of the Improved Drought Early Warning and Forecasting to Strengthen Preparedness and Adaptation to Droughts in Africa (DEWFORA) project under Grant Agreement 265454.

Edited by: M. Werner

\section{References}

Belo-Pereira, M., Dutra, E., and Viterbo, P.: Evaluation of global precipitation data sets over the Iberian Peninsula, J. Geophys. Res., 116, D20101, doi:10.1029/2010jd015481, 2011.

Buizza, R., Bidlot, J.-R., Wedi, N., Fuentes, M., Hamrud, M., Holt, G., and Vitart, F.: The new ECMWF VAREPS (Variable Resolution Ensemble Prediction System), Q. J. Roy. Meteor. Soc., 133, 681-695, doi:10.1002/qj.75, 2007.

Dee, D. P., Uppala, S. M., Simmons, A. J., Berrisford, P., Poli, P., Kobayashi, S., Andrae, U., Balmaseda, M. A., Balsamo, G., Bauer, P., Bechtold, P., Beljaars, A. C. M., van de Berg, L., Bidlot, J., Bormann, N., Delsol, C., Dragani, R., Fuentes, M., Geer, A. J., Haimberger, L., Healy, S. B., Hersbach, H., Hólm, E. V., Isaksen, L., Kållberg, P., Köhler, M., Matricardi, M., McNally, A. P., Monge-Sanz, B. M., Morcrette, J. J., Park, B. K., Peubey, C., de Rosnay, P., Tavolato, C., Thépaut, J. N., and Vitart, F.: The ERA-Interim reanalysis: configuration and performance of the data assimilation system, Q. J. Roy. Meteor. Soc., 137, 553-597, doi:10.1002/qj.828, 2011.

Di Giuseppe, F., Molteni, F., and Tompkins, A. M.: A rainfall calibration methodology for impacts modelling based on spatial mapping, Q. J. Roy. Meteor. Soc., 139, 1389-1401, doi:10.1002/qj.2019, 2013a.

Di Giuseppe, F., Molteni, F., and Dutra, E.: Real-time correction of ERA-Interim monthly rainfall, Geophys. Res. Lett., 40, 37503755, doi:10.1002/grl.50670, 2013b.

Dinku, T., Ceccato, P., Grover-Kopec, E., Lemma, M., Connor, S. J., and Ropelewski, C. F.: Validation of satellite rainfall products over East Africa's complex topography, Int. J. Remote Sens., 28, 1503-1526, doi:10.1080/01431160600954688, 2007.

Dutra, E., Di Giuseppe, F., Wetterhall, F., and Pappenberger, F.: Seasonal forecasts of droughts in African basins using the Standardized Precipitation Index, Hydrol. Earth Syst. Sci., 17, 23592373, doi:10.5194/hess-17-2359-2013, 2013a.

Dutra, E., Magnusson, L., Wetterhall, F., Cloke, H. L., Balsamo, G., Boussetta, S., and Pappenberger, F.: The 2010-2011 drought in the Horn of Africa in ECMWF reanalysis and seasonal forecast 
products, Int. J. Climatol., 33, 1720-1729, doi:10.1002/joc.3545, 2013b.

EM-DAT: The OFDA/CRED International Disaster Database, available at: www.emdat.be, last access: December 2013.

Gebremichael, M., Krajewski, W. F., Morrissey, M., Langerud, D., Huffman, G. J., and Adler, R.: Error Uncertainty Analysis of GPCP Monthly Rainfall Products: A Data-Based Simulation Study, J. Appl. Meteor., 42, 1837-1848, doi:10.1175/15200450(2003)042<1837:euaogm>2.0.co;2, 2003.

Giorgi, F. and Francisco, R.: Uncertainties in regional climate change prediction: a regional analysis of ensemble simulations with the HADCM2 coupled AOGCM, Clim. Dynam., 16, 169182, doi:10.1007/p100013733, 2000.

Gobron, N., Pinty, B., Mélin, F., Taberner, M., Verstraete, M. M., Robustelli, M., and Widlowski, J.-L.: Evaluation of the MERIS/ENVISAT FAPAR product, Adv. Space Res., 39, 105115, doi:10.1016/j.asr.2006.02.048, 2007.

GPCC Full Data Reanalysis Version 6.0 at $1.0^{\circ}$ : Monthly Land-Surface Precipitation from Rain-Gauges built on GTS-based and Historic Data, [Data set], doi:10.5676/DWD_GPCC/FD_M_V6_100, 2011b.

Hao, Z. and AghaKouchak, A.: Multivariate Standardized Drought Index: A parametric multi-index model, Adv. Water Resour., 57, 12-18, doi:10.1016/j.advwatres.2013.03.009, 2013.

Huffman, G. J., Bolvin, D. T., Nelkin, E. J., Wolff, D. B., Adler, R. F., Gu, G., Hong, Y., Bowman, K. P., and Stocker, E. F.: The TRMM Multisatellite Precipitation Analysis (TMPA): QuasiGlobal, Multiyear, Combined-Sensor Precipitation Estimates at Fine Scales, J. Hydrometeor., 8, 38-55, 2007.

Huffman, G. J., Adler, R. F., Bolvin, D. T., and Nelkin, E. J.: The TRMM Multi-satellite Precipitation Analysis (TMPA), in: Satellite Rainfall Applications for Surface Hydrology, edited by: Hossain, F. and Gebremichael, M., Springer Verlag, 3-22, 2010.

Kumar, A., Chen, M., Hoerling, M., and Eischeid, J.: Do extreme climate events require extreme forcings?, Geophys. Res. Lett., 40, 3440—3445, doi:10.1002/grl.50657, 2013.

Liebmann, B., Bladé, I., Kiladis, G. N., Carvalho, L. M. V., Senay, G. B., Allured, D., Leroux, S., and Funk, C.: Seasonality of African Precipitation from 1996 to 2009, J. Climate, 25, 43044322, doi:10.1175/jcli-d-11-00157.1, 2012

Mckee, T. B., Doesken, N. J., and Kleist, J.: The relationship of drought frequency and duration to time scales, in: Eight Conference on Applied Climatology, Anahaim, California, 179-184, 1993.

Naumann, G., Barbosa, P., Carrao, H., Singleton, A., and Vogt, J.: Monitoring Drought Conditions and Their Uncertainties in Africa Using TRMM Data, J. Appl. Meteorol. Clim., 51, 18671874, doi:10.1175/jamc-d-12-0113.1, 2012.

Naumann, G., Dutra, E., Barbosa, P., Pappenberger, F., Wetterhall, F., and Vogt, J. V.: Comparison of drought indicators derived from multiple data sets over Africa, Hydrol. Earth Syst. Sci., 18, 1625-1640, doi:10.5194/hess-18-1625-2014, 2014.

Palmer, T., Buizza, R., Hagedorn, R., Lawrence, A., Leutbecher, M., and Smith, L.: Ensemble prediction: A pedagogical prespective, ECMWF Newsletter, 106, 10-17, 2006

Pozzi, W., Sheffield, J., Stefanski, R., Cripe, D., Pulwarty, R., Vogt, J. V., Heim, R. R., Brewer, M. J., Svoboda, M., Westerhoff, R., van Dijk, A. I. J. M., Lloyd-Hughes, B., Pappenberger, F., Werner, M., Dutra, E., Wetterhall, F., Wagner, W., Schubert, S.,
Mo, K., Nicholson, M., Bettio, L., Nunez, L., van Beek, R., Bierkens, M., de Goncalves, L. G. G., de Mattos, J. G. Z., and Lawford, R.: Toward Global Drought Early Warning Capability: Expanding International Cooperation for the Development of a Framework for Monitoring and Forecasting, B. Am. Meteorol. Soc., 94, 776-785, doi:10.1175/bams-d-11-00176.1, 2013.

Schneider, U., Becker, A., Finger, P., Meyer-Christoffer, A., Rudolf, B., and Ziese, M.: GPCC Monitoring Product: Near Real-Time Monthly Land-Surface Precipitation from RainGauges based on SYNOP and CLIMAT data, [Data set], doi:10.5676/DWD_GPCC/MP_M_V4_100, 2011a.

Sepulcre-Canto, G., Horion, S., Singleton, A., Carrao, H., and Vogt, J.: Development of a Combined Drought Indicator to detect agricultural drought in Europe, Nat. Hazards Earth Syst. Sci., 12, 3519-3531, doi:10.5194/nhess-12-3519-2012, 2012.

Sheffield, J., Wood, E. F., and Roderick, M. L.: Little change in global drought over the past 60 years, Nature, 491, 435-438, doi:10.1038/nature11575, 2012.

Shukla, S., Steinemann, A. C., and Lettenmaier, D. P.: Drought Monitoring for Washington State: Indicators and Applications, J. Hydrometeorol., 12, 66-83, doi:10.1175/2010JHM1307.1, 2011.

Svoboda, M., LeComte, D., Hayes, M., Heim, R., Gleason, K., Angel, J., Rippey, B., Tinker, R., Palecki, M., Stooksbury, D., Miskus, D., and Stephens, S.: The Drought Monitor, B. Am. Meteorol. Soc., 83, 1181-1190, doi:10.1175/15200477(2002)083<1181:tdm>2.3.co;2, 2002.

Tadesse, T., Wilhite, D. A., Harms, S. K., Hayes, M. J., and Goddard, S.: Drought monitoring using data mining techniques: A case study for Nebraska, USA, Nat. Hazards, 33, 137-159, doi:10.1023/B:NHAZ.0000035020.76733.0b, 2004.

Teuling, A. J., Van Loon, A. F., Seneviratne, S. I., Lehner, I., Aubinet, M., Heinesch, B., Bernhofer, C., Grünwald, T., Prasse, H., and Spank, U.: Evapotranspiration amplifies European summer drought, Geophys. Res. Lett., 40, 2071-2075, doi:10.1002/grl.50495, 2013.

Van Loon, A. F. and Van Lanen, H. A. J.: Making the distinction between water scarcity and drought using an observationmodeling framework, Water Resour. Res., 49, 1483-1502, doi:10.1002/wrcr.20147, 2013.

Vicente-Serrano, S. M., Begueria, S., and Lopez-Moreno, J. I.: A Multiscalar Drought Index Sensitive to Global Warming: The Standardized Precipitation Evapotranspiration Index, J. Climate, 23, 1696-1718, doi:10.1175/2009jcli2909.1, 2010.

Vicente-Serrano, S. M., Beguería, S., Lorenzo-Lacruz, J., Camarero, J. J., López-Moreno, J. I., Azorin-Molina, C., Revuelto, J., Morán-Tejeda, E., and Sánchez-Lorenzo, A.: Performance of drought indices for ecological, agricultural and hydrological applications, Earth Interact., 16, 1-27, doi:10.1175/2012ei000434.1, 2012.

Webster, P. J.: Meteorology: Improve weather forecasts for the developing world, Nature, 493, 17-19, 2013.

Ziese, M., Becker, A., Peter, F., Meyer-Christoffer, A., Rudolf, B., and Schneider, U.: GPCC Drought Index Product (GPCC_DI) at $1.0^{\circ}$, [Data set], doi:10.5676/DWD_GPCC/DI_M_100, 2011a.

Ziese, M., Becker, A., Finger, P., Meyer-Christoffer, A., Rudolf, B., and Schneider, U.: GPCC First Guess Product at $1.0^{\circ}$ : Near Real-Time First Guess monthly Land-Surface Precipitation from Rain-Gauges based on SYNOP Data, [Data set], doi:10.5676/DWD_GPCC/FG_M_100, 2011 b. 